\title{
An Animal World Map
}

Pan Cheng ${ }^{1}$

${ }^{1}$ Journal of Conceptual and Applied STEM Education

April 28, 2020

\section{Grade Level: 4th}

\section{Suggested Time: 50 minutes}

\section{Overview}

Students will work in small groups, and each group will be assigned a continent. Each group will use online resources to research their assigned continent's climate zone, geography, and animals. Then the groups will use different project materials to create posters to present what they found out about the continent. At the end of this lesson, the class will combine all the continents to form a map of the Earth, and students will discuss the map.

\section{Vocabulary}

Africa, Antarctica, Asia, Australia, Climate, Climate Zone, Continents, Europe, Fahrenheit, Geography, North America, Polar Zone, South America, Temperate Zone, Tropical Zone

\section{Objectives}

- Students will work in small groups to use online resources to search for information about the assigned continent.

- Each group will use project materials, such as colored markers, sticky notes, and animal stickers, to design a poster that presents information about the continent, including climate, geography, and animals.

- Students will combine all the continent posters to form a map of the Earth and discuss the map.

\section{Required Project Materials}

- Laptops and iPads with Internet access

- GoodNotes app on iPads

- Poster paper with the outline of a specific continent

- Sticky notes

- Colored markers

- Animal stickers 
- Tape

\section{Multimedia Resources}

- Ella Cane. Continents in My World. https://www.amazon.com/Continents-My-World-Ella-Cane/ $\mathrm{dp} / 1476531234 /$ ref=sr_1_1?dchild=1\&keywords=continents+in+my+world\&qid=1587670112\&sr=81

- Dr. Binocs from Peekaboo Kidz. The Dr. Binocs Show - Climate Zones of the Earth. https://www . youtube . com/watch?v=5tC800x0FEk

- Online books related to different continents on myon.com

- Online books and educational videos about different continents on getepic.com

\section{Optional Multimedia Resources}

- CleverBooks augmented reality world map

\section{Before the Lesson/Background Information}

- Divide the students into seven groups of four

- Prepare poster papers with an outline of a continent on each one

\section{The Lesson}

\section{Part 1: The Seven Continents and the Three Climate Zones (10 minutes)}

1. The whole class reads Ella Cane's read-to-me online book, Continents in My World, to develop a basic understanding of the seven continents.

2. Discuss: How are the seven continents different?

3. The whole class watches The Dr. Binocs Show - Climate Zones of the Earth on YouTube.com to develop a basic understanding of the three climate zones.

4. Discuss: How do we use different temperatures to represent each climate zone? How do the three climate zones affect the animals that live on the seven continents?

\section{Part 2: Researching a Continent (15 minutes)}

1. Students are divided into groups of four. Each group is assigned a specific continent.

2. Students use laptops to access different online resources, such as myon.com and getepic.com, to search for information on their assigned continent. They take notes using the GoodNotes app on their iPads.

3. Discuss: How can you help other groups understand your continent, including climate, geography, and animals? The climate information should include the temperature on the continent in Fahrenheit. The geography information should include the continent's area in square miles. The animal information should include the animals' appearances and behaviors.

4. Students brainstorm their notes and select useful information for their continent assignment. 


\section{Part 3: Creating a Poster about a Continent (15 minutes)}

1. Each group is given colored markers, sticky notes, animal stickers, and a poster paper with an outline of their assigned continent.

2. Each group uses the project materials to create a meaningful and informative poster that shows their understanding of their assigned continent, including climate, geography, and animals.

3. After the students spend eight minutes designing their posters, each group sends two students to look at other groups' posters. Students exchange their design ideas among groups.

4. After exchanging poster design ideas, students improve their poster designs.

\section{Part 4: Forming a Map of the World (10 minutes)}

1. All the groups put their posters on the classroom whiteboard to form a map of the Earth. The whole class takes ten minutes to discuss the relationship among the seven continents, three climate zones, and many kinds of animals.

2. When students compare and contrast the geographies of the different continents, students should use different temperatures and areas in square miles to support their opinions.

3. Discuss: Why do animals have appearances and behave in specific ways on each continent? How do the seven continents and the three climate zones affect the animals' lifestyles?

4. The teacher keeps all the continent posters for future teaching and learning. The teacher takes photos of the posters and posts the photos on the school's STEM web page and Twitter.

\section{Homework}

- The teacher assigns students to read Diyan Leake's Oceans and Sea. Each student should create a diagram that shows a map of the Earth and the five oceans.

\section{Standards}

- Next Generation Science Standards. 4-LS1-1: Construct an argument that plants and animals have internal and external structures that function to support survival, growth, behavior, and reproduction.

- International Society for Technology Standard. ISTE Students 4a: Students know and use a deliberate design process for generating ideas, testing theories, creating innovative artifacts or solving authentic problems.

- NYS CTE - Standard 5 - Engineering Design: Generate ideas for possible solutions, individually and through group activity; apply age-appropriate mathematics and science skills; evaluate the ideas and determine the best solution; and explain reasons for the choices.

- NYS Common Core Math Standard. CCSS.MATH.CONTENT.4.MD.A.1: Know relative sizes of measurement units within one system of units including km, m, cm; kg, g; lb, oz.; l, ml; hr, min, sec. Within a single system of measurement, express measurements in a larger unit in terms of a smaller unit. 